\title{
Os Terena na História
}

\section{The Terena in History}

\author{
Luciano Araujo Monteiro ${ }^{1}$
}

DOI: http://dx.doi.org/10.20435/tellus.v19i39.561

Resumo: Nas últimas décadas temos assistido ao crescente protagonismo indígena nos movimentos políticos referentes à sua causa. O número de organizações indígenas tem aumentado, bem como os eventos que discutem essa temática, nos quais os próprios indígenas se constituem como lideranças, e também, intelectuais que problematizam tais questões nas universidades e nas publicações acadêmicas. A saber, o livro: "A História do Povo Terena" é um produto dessa realidade, em que, essa etnia busca, por meio da História Oral, resgatar suas origens. O objeto de estudo é a análise deste livro, como forma e conteúdo, visando compreender o discurso, seja iconográfico, seja textual, inserido nessa produção didática, criada pelos Terena e para eles.

Palavras-chave: livro didático; educação diferenciada; Terena.

Abstract: In the last decades we have witnessed the increasing indigenous protagonism in the political movements related to its cause. The number of indigenous organizations has increased, as well as the events that discuss this theme, in which indigenous people themselves constitute leaderships, as well as intellectuals who problematize such issues in universities and academic publications. Namely, the book "History of the Terena People" is a product of this reality, in which, this ethnicity seeks, through Oral History, to rescue its origins. The object of study is the analysis of this book, as form and content, aiming to understand the discourse, whether iconographic or textual, inserted in this didactic production, created by Terena and for them.

Keywords: Textbook, Differentiated education; Terena.

\section{INTRODUÇÃO}

Nas últimas décadas temos assistido ao crescente protagonismo indígena nos movimentos políticos referentes à sua causa. O número de organizações

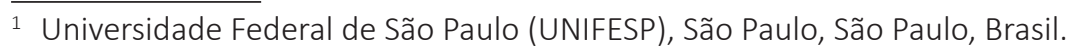


indígenas ${ }^{2}$ tem aumentado, bem como os eventos que discutem essa temática, nos quais os próprios indígenas se constituem como lideranças, e também, intelectuais que problematizam tais questões nas universidades e nas publicações acadêmicas. Nesse sentido, ganham volume os debates que apontam novas perspectivas de se observar e encaminhar as questões indígenas, entre elas às relativas à educação. Desde a Constituição de 1988, está "assegurada às comunidades indígenas também a utilização de suas línguas maternas e processos próprios de aprendizagem" (Artigo 210, § 2ํ), ou seja, Ihes é assegurado uma educação diferenciada e bilíngue.

Nesse contexto de novos rumos dados à educação (Terena) é que se insere nosso objeto de estudo, a saber, o livro didático: "A História do Povo Terena" sendo que, o título deste artigo é homônimo ao terceiro capítulo da monografia de conclusão de curso, que foi elaborada utilizando esta fonte histórica, defendida no âmbito da universidade (no estudo monográfico há um aprofundamento dessa temática). Trata-se de um livro pouco conhecido e bastante específico, destinado a ser utilizado na educação escolar dos Terena ${ }^{4}$ (povo que reside em São Paulo [município de Tupã], Mato Grosso e do Mato Grosso do Sul) ${ }^{5}$, mais precisamente, essa obra didática é destinada aos jovens Terena que residem nos centros urbanos do Mato Grosso do Sul, se diferenciando por ser um material didático organizado pelo Centro de Trabalho Indigenista $(\mathrm{CTI})^{6}$, em parceria com

2 Para ter acesso a informações sobre as organizações indígenas presentes nos vários estados da federação, acesse: http://pib.socioambiental.org/pt/c/iniciativas-indigenas/organizacoes-indigenas/lista-de-organizacoes. Acesso em: jan. 2014.

3 Essa obra didática está disponível em: http://lemad.fflch.usp.br/sites/lemad.fflch.usp.br/ files/A\%20Historia\%20do\%20Povo\%20Terena.pdf. Acesso em: fev. 2017.

4 A língua Terena deriva da língua Aruak, que, por sua vez, congregou um conjunto de povos indígenas que viviam na região das Guianas e em algumas ilhas do Caribe. Ao ter o contato com o europeu, houve povos que se deslocaram mais ao sul do que hoje se conhece por Brasil. Foi graças à colonização europeia que os Terena se encontram concentrados no Centro-Oeste (BITTENCOURT; LADEIRA, 2000).

5 Segundo informação obtida ao entrevistar a antropóloga Maria Elisa Ladeira (2013), um contingente de indígenas Terena foi deslocado da região Centro-Oeste para o oeste paulista, a fim de pacificar pela lógica do trabalho os indígenas da etnia Kaingang (na década de 1970), por conta do fato dos Terena serem vistos como pessoas ordeiras e bons trabalhadores.

6 "O Centro de Trabalho Indigenista - CTI é uma Organização como associação sem fins lucrativos, fundada em março de 1979 por antropólogos e indigenistas que já trabalhavam com alguns grupos indígenas do Brasil". 
o Ministério da Educação (com financiamento público, no que diz respeito a sua impressão). Justificamos a importância de analisar esse livro pelo fato deste se inserir na problematização da educação escolar indígena diferenciada, que ocorre em nossos dias, além de contribuir para o debate sobre esse tipo de produção didática, abordando um livro que se constitui como especificidade e originalidade nesse campo. Este livro se constitui como desdobramento de um curso de formação, organizado pela Universidade de São Paulo (USP) e pelo Centro de Trabalho Indigenista, voltado para professores indígenas ${ }^{7}$.

Por outro lado, em se tratando de uma monografia inserida num curso de História, este trabalho se justifica porque amplia as possibilidades de discutir o ensino de História indígena no âmbito da lei n. 11.645/2008, que torna obrigatório o ensino dessa temática na Educação Básica.

Este estudo tem por objetivos discutir o processo de elaboração dessa obra, realizar a análise dos conteúdos textual e iconográfico do livro didático, entendendo também, a forma como o conteúdo foi estruturado, a fim de perceber este objeto de monografia no contexto de autodeterminação dos povos indígenas, no que diz respeito a uma educação diferenciada e bilíngue, compreendendo o discurso dessa obra pela perspectiva do povo Terena e pelo desejo destes de se inserir na história nacional, tendo como grande marco temporal a Guerra do Paraguai (momento em que estes pegam em armas para defender o território brasileiro).

\section{A IMPORTÂNCIA DESSA PRODUÇÃO DIDÁTICA}

Podemos entender este livro didático como um material complexo, pelo fato deste livro agregar diversas informações de cunho histórico, seja por meio do conteúdo textual, seja por intermédio da iconografia, conferindo ao livro didático a função documental, pois: [...] acredita-se que o livro didático pode fornecer, sem que essa leitura seja dirigida, um conjunto de documentos, textuais ou icônicos, cuja confrontação pode vir a desenvolver o espírito crítico do aluno (CHOPPIN, 2004, p. 553).

Fonte: http://www.trabalhoindigenista.org.br/pagina.php?p=quem_somos.php. Acesso em: 23 ago. 2013.

7 Esta informação foi obtida ao entrevistar Circe Bittencourt e Maria Elisa Ladeira (2013). 
Em outras palavras, esse autor apresenta o papel desse material para inserir o aluno no universo da cidadania, isto é, torná-lo consciente de seus direitos e deveres. Assim como este escritor chama a atenção para a importância de se estudar a recepção desse segmento de obra entre professores e alunos (CHOPPIN, 2004), aspecto que, embora relevante, não contemplaremos nessa pesquisa, dado o escopo desse trabalho.

Ao pensarmos nesse tipo de livro como um produto cultural complexo, podemos supor também, segundo Alain Choppin, que: "Conclui-se que a imagem da sociedade apresentada pelos livros didáticos corresponde a uma reconstrução que obedece à motivações diversas, segundo época e local [...]. O livro didático não é um simples espelho: ele modifica a realidade para educar as novas gerações [...]" (CHOPPIN, 2004, p. 557).

Isto é, ao pensarmos no "A História do Povo Terena", é possível supor que este livro cumpre uma função social, à medida que trabalha a história como processo, rompendo com uma visão estática de que a realidade sempre foi daquele jeito, ao pensarmos no tempo presente. Além disso, ao estabelecer uma relação entre passado e presente, esta fonte não deixa de possuir as marcas do tempo e espaço no qual foi concebida (CHOPPIN, 2004, p. 564).

Pensamos que seja coerente acrescentar a este estudo algumas exigências presentes no Programa Nacional do Livro Didático (PNLD), de 2011, no que diz respeito aos requisitos para que uma obra didática de história seja considerada de qualidade satisfatória:

Neste segmento de ensino fundamental, o livro didático deve contribuir para o desenvolvimento dos conceitos de História, fonte, historiografia, memória, acontecimento, sequência, encadeamento, períodos, fato, tempo, simultaneidade, ritmos de tempo, medidas de tempo, sujeito histórico, espaço, historicidade, identidade, semelhança, diferença, contradição, continuidade, permanência, mudança, evidência, causa, ficção, narrativa, verdade, ruptura, explicação e interpretação. (BRASIL, 2011, p. 46-7).

Essa fonte documental, especificamente, referente a um livro didático sobre a história do povo Terena, nos ajuda a compreender a história em suas particularidades, desmistificando assim, o ideal de uma identidade nacional única, homogênea e comum. Nesse sentido, Leite nos mostra a importância do livro didático regional, a fim de produzir uma identidade social ou mesmo individualidades: 
Dessa forma, uma geração produz configurações intelectuais múltiplas e simultâneas através das quais a realidade é construída, por isso é possível afirmar que diferentes grupos constroem diferentes realidades. (LEITE, 2007, 195).

[...] não se pode deixar de considerar que o livro didático regional de História, enquanto objeto cultural que suporta uma prática cultural de escrita de si é instrumento formador de subjetividades e, portanto, merece ser apreciado em pesquisas que possibilitem a ampliação de sua compreensão. (LEITE, 2007, p. 196).

Em minhas pesquisas, tornou-se notório o papel dos livros didáticos para criar identidades ou memórias, contudo, esse material didático não é o responsável exclusivo por essa função. Assim como, devemos lembrar que ele pode se articular a outros veículos de comunicação, tendo, por fim, forjar e/ou cristalizar representações, assim como a memória. Segundo Bittencourt:

Sobre as relações entre conteúdos escolares e acadêmicos, o historiador Carlos Vesentini, no artigo 'Escola e livro didático de História', apontou para especificidades do livro didático no processo de criação e cristalização de uma memória, na consolidação de determinados fatos considerados fundamentais nas mudanças de nossa sociedade. O autor adverte-nos, no entanto, de que o livro didático não é responsável de forma isolada por essa sedimentação de uma memória histórica [...]. (BITTENCOURT, 2008, p. 304).

Em outras palavras, esse material não é o exclusivo responsável por ditar uma "verdade" ou uma representação. Como exemplo, voltamos às diversas mídias que, em paralelo ao livro didático, moldam, por assim dizer, determinados modo de ser.

Este livro de história Terena não se insere apenas no momento de autodeterminação dos povos indígenas, mas também, como uma alternativa temática, pois, apesar da existência da lei n. 11.645/2008, que torna obrigatório o ensino de história indígena, nota-se a ausência desses grupos nos materiais didáticos contemporâneos, segundo enfatiza Circe Bittencourt:

Os discursos nos textos didáticos também têm sido analisados, sobretudo para identificar a manutenção de estereótipos sobre grupos étnicos. No caso das populações indígenas, os educadores e antropólogos têm-se preocupado com a permanência de visões deformadoras e incompletas sobre esses povos. Algumas de suas análises identificam a ausência de estudos sobre a história indígena, situação que dificulta igualmente mudanças na produção 
didática. As populações indígenas surgem nos livros didáticos nos capítulos iniciais, quando da chegada dos europeus e para justificar a importação de mão de obra escrava africana, embora em alguns mais recentes apareçam alguns dados sobre as condições atuais desses povos. Os índios, mesmo em obras mais críticas, são apresentados em seus aspectos gerais, com análises mais estruturais empenhadas em rebater as teorias raciais que buscavam culpá-los pela herança deixada ao povo brasileiro, a saber, 'a índole avessa ao trabalho produtivo'. (BITTENCOURT, 2008, p. 305).

O livro de temática indígena aqui apresentado busca não simplesmente "dar voz", mas escutar a voz dos Terena, tornados sujeitos, pensando a História por sua perspectiva, e que se insere num momento histórico, no qual a educação deixa de ser pensada para o indígena, tornando-se uma educação dos indígenas, seja por meio de reprodução dos relatos orais, seja por intermédio de iconografia que representam sua cultura.

Atualmente, os Terena veem na educação uma forma de superar essa situação de exclusão, de acordo com a análise de Ladeira: "[...] a escola é encarada, por setores consideráveis das comunidades Terena, como um instrumento de ascensão individual, a possibilidade de seus filhos escaparem da vida 'sem futuro' na aldeia e nas usinas de álcool" (LADEIRA, 2001, p. 43).

Mariano Marcos Terena também reforça o quanto é necessário à capacitação intelectual, para que os indígenas, de fato, sejam agentes de sua própria história:

Mas aprendeu [o indígena] que, para continuar vivendo era necessário conviver com os costumes da sociedade branca. Aprendeu que era necessário instruir-se, ler e escrever, conhecer métodos de agricultura, pecuária e se possível ter um índio 'doutor', afinal, a capacidade de aprendizado, o potencial existente dentro de si era o mesmo que qualquer outro ser humano.

Durante toda minha vida aprendi que para ser respeitado era necessário respeitar, e que o índio precisava desenvolver-se, instruir-se para que pudesse galgar em mesmo pé de igualdade os diversos setores da sociedade envolvente. (TERENA, 1981, p. 40).

Nos dias atuais, os Terena são valorizados como bons agricultores, bons comerciantes, pessoas ordeiras, de acordo com informações obtidas em entrevistas com as autoras dessa obra. Maria Elisa Ladeira chegou e expor que o modelo de vida deles já foi levado para outros povos, por iniciativa governamental, conforme informado em: 
Ao mesmo tempo em que o $\mathrm{SPI}^{8}$ e posteriormente a Funai consolidavam uma série de mecanismos que impediam a auto-sustentação da comunidade Terena dentro das reservas, voltando-as para o trabalho externo, 'elegeram' os Terena como um dos grupos mais adaptados à sua proposta de integração do índio à 'comunhão nacional', devido a seu longo e amistoso contato com a população regional. O rótulo de 'semiaculturados' fez com que o SPI deslocasse famílias Terena para outras áreas indígenas (Guarani, Kadiwéu, Kaingang) para que estes 'aprendessem' com os Terena. Essa posição 'privilegiada' ocupada pelos Terena foi também a responsável pela introdução da escola pelo SPI em algumas comunidades, inclusive a de Cachoeirinha, ainda na primeira metade do século XX. O objetivo declarado dessas escolas era 'apressar' o processo de aculturação dos Terena. Data deste período a elaboração de todo um discurso segundo o qual 'não há futuro no interior da reserva', fundamental para a compreensão do papel da escola no imaginário Terena. (LADEIRA, 2001, p. 42).

Ladeira também informou em entrevista que um dos primeiros povos que o governo nacional quis emancipar foi os Terena. Todavia, devemos frisar que, se por um lado a emancipação era um documento legal que conferia o status de cidadão ao indígena, por outro, era um dispositivo de autonegação da própria origem, segundo nos informa Marcos Terena: "[...] emancipação esta que nada Ihe acrescenta de útil ou benéfico, mas Ihe tira o direito de existir como indígena e como tal de lutar pela justiça para com os seus" (TERENA, 1981, p. 39).

O livro "A História do Povo Terena" foi fruto do desdobramento de um curso de formação destinado a professores indígenas, dentre eles, os Terena, que tinham por objetivo inicial o de estruturar o próprio currículo educacional de História. Foi um curso ministrado na Faculdade de Educação da Universidade de São Paulo (na primeira metade da década de 1990), realizado em parceria com o Centro de Trabalho Indigenista. Segundo Bittencourt, em entrevista (2013), os Terena queriam organizar o currículo de História, pelo fato de se perceberem fora da História do Brasil, por não serem mencionados em sua participação num episódio o qual eles têm o maior orgulho, que é a Guerra do Paraguai.

Com o intuito de reunir a documentação escrita para a confecção dessa obra, alguns alunos de Circe Bittencourt realizaram estágio dentro das reservas Terena, conforme esta historiadora relatou em entrevista concedida a mim:

\footnotetext{
8 Serviço de Proteção ao Índio - "Da data de sua criação [1910] até sua substituição, em 1967, pela Fundação Nacional do Índio (FUNAI), o SPI funcionou vinculado a diferentes ministérios. De 1910 a 1930 esteve vinculado ao Ministério da Agricultura, Indústria e Comércio [...]" (CHAMUSCA; GESTEIRA; GRILLO; HENRIQUES, 2007, p. 23).
} 
Para fazer esse livro, naquela ocasião, eu dava aulas de Prática de Ensino. Foi feito um acordo também com o CTI, os alunos de Prática de Ensino, meus alunos, que quisessem fazer estágio em escolas indígenas lá deles, [...] ficavam em geral um mês fazendo estagio nas escolas indígenas, em especifico dos Terena. Eles foram recolhendo junto comigo toda a documentação escrita sobre os Terena [...]. (BITTENCOURT, 2013).

Contudo, ainda havia a escassez documental (escrita). Com o objetivo de resgatar a cultura Terena, optou-se pelo uso dos relatos orais, conforme apontado por Ladeira em entrevista concedida a mim:

Eu acho que eles não tinham essa concepção para eles, ou ao contrário, que a gente procurou demonstrar para eles é que, os relatos orais eram um documento, tinha um valor de documento e isso a Circe [Bitttencourt] enfatizava muito, porque no começo eles tinham uma certa resistência, por que eles diziam: 'Bom, a gente não tem nada'. Eles não tinham nada escrito. Então toda coisa ela dizia: 'Não, os relatos orais são uma fonte sim de documentação para que a gente possa constituir'. Então, vamos fazer pesquisa com os mais velhos, vão lembrar de histórias que vocês escutaram, vamos fazer reflexão e vamos disponibilizar dentro do material, as fontes escritas, históricas, escritas nossas, do Taunay, [...], ao Rondon [...]. (LADEIRA, 2013 ).

Em outras palavras, por conta da escassez documental, optou-se por resgatar as tradições e mitos desse grupo indígena por intermédio do relato oral, elevando-os ao status de fonte histórica, ao mesmo tempo em que eram escoIhidas peças da cultura material que são fruto da produção artística deste povo (para serem retratadas) e iconografia que os apresentam como pessoas ordeiras, trabalhadoras e preocupadas com a educação. Sem esquecermos de que, tanto Taunay quanto Rondon são citados pelo viés histórico mais tradicional, enquanto este foi responsável pela demarcação das reservas Terena, aspecto que pôs fim ao Tempo de Servidão ${ }^{9}$, aquele retratou os Terena no século XIX, como na pintura Retirada da Laguna (BITTENCOURT; LADEIRA, 2000, p. 54), no contexto da Guerra do Paraguai. Estas escolhas, assim como a fé que os Terena depositam na educação e a atuação deste povo em obras públicas, como a expansão da linha telegráfica e da malha ferroviária (Estrada de Ferro Noroeste do Brasil) os tornam agentes históricos e não meros coadjuvantes.

9 Logo após a Guerra do Paraguai, o governo imperial premiou membros da Guarda Nacional, ofertando a estes oficiais territórios ocupados pelos Terena. Além da perda de territórios, o Tempo da Servidão é marcado pela escravização dessa etnia pelos fazendeiros que se estabeleciam no que hoje chamamos de Região Centro-Oeste. 
O livro, escrito e organizado por Circe Bittencourt e Maria Elisa Ladeira (composto por textos que retratam os mitos Terena, assim como iconografia escolhida por essa etnia para compor a obra didática), contém 156 páginas e está escrito em português, conforme recomendado pelos Terena. Esse pedido pode ser entendido como um mecanismo de luta, ou seja, o uso do português, que é a língua do dominador, se torna um instrumento de embate com o não indígena, a fim de requerer melhorias sociais, segundo foi relatado em entrevista por Ladeira (2013). Nesta mesma entrevista, Ladeira mencionou que há muitos Terena formados em Pedagogia e que dão aulas nas aldeias, ou seja, isto é mais um sinal da crença que estes indígenas conferem à educação e na importância de gerir o próprio processo educacional, com o intuito de continuar promovendo sua própria autodeterminação. Além disso, nesta obra didática também é citada a Associação Indígena Terena de Cachoeirinha (AITECA), que reúne lideranças dessa aldeia e que trás, como uma pauta de interesse, a questão da educação, mostrando assim que essa etnia não é figurante da História, mas sim, composta por agentes históricos, que visam uma transformação no âmbito social, por intermédio das práticas educacionais e pedagógicas. Ou seja, se na primeira metade do século XX houve iniciativas governamentais para que existissem escolas em território Terena (pensadas pelo não indígena para os indígenas), nos dias atuais, estas instituições de ensino contam com professores desse grupo étnico, que se dedicam a levar adiante o ensino, conforme é garantido pela Constituição Federal de 1988. Ademais, o estímulo ao ensino relacionado à temática indígena também é reforçado por intermédio da criação da lei n. 11.645/2008, por estabelecer a obrigatoriedade dessa modalidade de ensino, assim como a transmissão da historia africana e dos afrodescendentes, seja no ensino fundamental, seja no ensino médio (em escolas públicas e privadas), conforme evidenciamos a seguir:

Art. 26-A. Nos estabelecimentos de ensino fundamental e de ensino médio, públicos e privados, torna-se obrigatório o estudo da história e cultura afro-brasileira e indígena.

$\S 1$ O O conteúdo programático a que se refere este artigo incluirá diversos aspectos da história e da cultura que caracterizam a formação da população brasileira, a partir desses dois grupos étnicos, tais como o estudo da história da África e dos africanos, a luta dos negros e dos povos indígenas no 
Brasil, a cultura negra e indígena brasileira e o negro e o índio na formação da sociedade nacional, resgatando as suas contribuições nas áreas social, econômica e política, pertinentes à história do Brasil. (BRASIL, 2008).

A capa e contracapa do livro (aparecem em tons de cor amarelo e laranja), de valor histórico (por ser a primeira representação oficial dos Terena), lembrando que, antes mesmo de serem retratados por Taunay, os Terena foram representados, por meio da Expedição Langsdorff, que visava fazer um mapeamento do território nacional, na década de 1820. Essa representação foi recuperada, tornando-se a capa e contracapa do livro, segundo informado por Bittencourt em entrevista: "Tem um relato que antecede que é a capa do livro, que é a viagem da Missão Langsdorff em que tem desenho, o primeiro desenho de branco sobre eles, que é exatamente a capa do livro. O desenho é a capa e a contracapa [...]" (BITTENCOURT, 2013).

As fotografias utilizadas ao longo da obra aparecem, ora em preto e branco, ora em cores, lembrando que, pelo fato dos Terena se preocuparem com a aparência, foram selecionadas imagens nas quais estes aparecem bem vestidos. Ladeira reforça esse ponto: "[...] nenhuma foto eles poderiam estar aparecendo nus ou estarem aparecendo maltrapilhos, rasgados [...]. Você pega e corta o pé da pessoa, eles não gostam [...]" (LADEIRA, 2013).

Por meio das imagens, podemos observar como os Terena gostam de estar representados, seja como indivíduos ordeiros, seja como pessoas de boa aparência: “Ou seja, eles participam 'do nosso mundo', e fazem questão de andar bem vestidos e limpos e de mandarem seus filhos estudar na cidade [...]" (LADEIRA, 2001, p. 37).

Conforme informação obtida em entrevista com as autoras dessa obra didática, a maior parte das ilustrações foi disponibilizada pelo Museu Nacional do Índio, do Rio de Janeiro. A outra parcela das imagens foi produzida por pessoas da comunidade Terena. Dentre as ilustrações que compõem o discurso desse livro, podemos destacar as fotografias localizadas no Capítulo V, tendo por subtítulo: "A FUNAI e a situação atual", por retratarem crianças em sala de aula (BITTENCOURT; LADEIRA, 2000, p. 100-1), aspecto que reflete a crença Terena na educação, como já mencionado anteriormente e que, também é reforçado por Ladeira:

Neste contexto é que os Terena creditam à escola, e à língua portuguesa por consequência, um papel fundamental na construção de seu futuro. Nos últimos 15 anos, o empenho dos pais para que seus filhos frequentem a 
escola na aldeia e os esforços para que consigam fazer o 'ginásio' na cidade têm sido imensos. (LADEIRA, 2001, p. 41).

Ao refletirmos sobre os aspectos metodológicos, como os exercícios apresentados no livro, notamos que estes permitem a participação ativa do aluno no processo de aprendizagem e na reflexão histórica. Os exercícios estimulam o trabalho comparativo entre as fontes, assim como, fixam a prática cognitiva, seja pela prática do desenho, seja por meio de uma atividade artesanal. Conforme aparece, por exemplo, em atividades como: "Escreva uma relação das fontes para se conhecer a história do povo Terena" (BITTENCOURT; LADEIRA, 2000); "Desenhe [...] como seria uma antiga aldeia Terena e compare com a que você mora. Procure construir, em miniatura, uma casa tradicional" (BITTENCOURT; LADEIRA, 2000). A partir dos exercícios, podemos notar a influência de Bittencourt, pois, na época do curso de formação, esta era professora de Prática de Ensino de História na Faculdade de Educação (USP).

O conteúdo textual está dividido em seis capítulos, subdivididos entre três e seis subtítulos (por exemplo, o capítulo III, intitulado: "Os Terena e a Guerra do Paraguai", está subdividido em: "A Guerra do Paraguai; Histórias da Guerra: relatos de Taunay; Histórias da guerra: relatos dos Terena"), sendo que, tanto a folha de rosto, quanto às páginas onde estão inseridos os títulos dos capítulos estão ornados com pinturas Terena, que vão do vermelho ao tom rosado. Esses desenhos, que remetem ao artesanato Terena, também estão presentes nas páginas dos textos, assim como nas propostas de atividades.

O texto está inserido em coluna única, permitindo uma leitura dinâmica, existindo sempre a combinação, entre textos didáticos e relatos orais. Já as imagens ocupam uma página ou página dupla, sendo que, o conjunto iconográfico (composto por fotografias e pinturas) é de fácil visualização.

Poderíamos incluir os Terena como participantes do desenvolvimento nacional, pois segundo Ladeira:

Após a guerra do Paraguai, dois fatos significativos marcariam a história Terena: a construção da Estrada de Ferro Noroeste do Brasil, responsável direta pelo significativo incremento populacional da região e a instalação da linha telegráfica que ligava o interior paulista à cidade de Cuiabá. A região se abria à instalação da atividade pecuária, e os dois empreendimentos reforçaram a ocupação dos territórios Terena pelos brasileiros. (LADEIRA, 2001, p. 21). 
No livro "A História do Povo Terena" (BITTENCOURT; LADEIRA, 2000, p. 79-80) há a menção destes como trabalhadores na implantação, tanto da linha telegráfica quanto da linha férrea, sendo que, na página 80 há uma representação fotográfica retratando os Terena erguendo os postes telegráficos. Há também a menção no subtítulo: "Estrada de Ferro Noroeste do Brasil" (p. 82-4), que explica esse episódio, algumas imagens ilustrativas que retratam, tanto a linha férrea como o caminho no qual a locomotiva passava. A partir desses episódios narrados no "A História do Povo Terena", podemos refletir sobre o que esse livro didático tem ao mostrar como fatos locais, não mencionados pela historiografia oficial, têm relevância para entendermos, em escala abrangente, as mudanças ocorridas no Brasil entre a segunda metade do século XIX e início do XX e a participação ativa do povo Terena nesses processos históricos. Nota-se também, por meio do discurso impresso, que, os Terena desejam aparecer, ou melhor, serem representados como os construtores da nação brasileira, por terem participado da Guerra do Paraguai (como fornecedores de alimentos e como combatentes), na implantação das linhas férrea e telegráfica.

O livro "A História do Povo Terena" também faz menção à exploração dessa população indígena, sendo que, nos dias atuais, permanece havendo uma forte tensão entre essa etnia de um lado e, do outro, policiais e latifundiários, ocasionando, em 2013, a morte do indígena Oziél Terena, que, segundo informado por Ladeira, foi assassinado pela polícia em Buriti, numa ação de reintegração de posse. O livro faz menção aos bugreiros, assassinos de indígenas que eram contratados por fazendeiros, representados em fotografia (BITTENCOURT; LADEIRA, 2000, 94), na qual estes posam junto de mulheres e crianças. Por meio da observação dessa imagem, é possível supor que, estes indígenas aparecem como troféus em meio ao extermínio dos homens.

Ademais, a obra didática analisada também faz menção ao termo: "changa", isto é, ao período de trabalho temporário em que o indígena deixa a aldeia para trabalhar nas fazendas ou usinas de cana de açúcar. Segundo foi dito por Maria Elisa Ladeira (2013), em entrevista, isso ocorre pelo fato da própria aldeia não garantir a subsistência dessa etnia, dado o volume populacional que nelas reside e este é um ponto que contribui para a desagregação familiar. A partir deste fato, podemos pensar em outra demanda do indígena, que é o direito ao território e ao manejo dos recursos naturais, com a finalidade de garantir a própria subsistência, 
como também, para fortalecer o próprio movimento indígena, pois se ele não tiver necessidade de abandonar seu lar, o grupo continuará coeso e terá maior força para reivindicar direitos sociais perante o Poder Público.

\section{CONSIDERAÇÕES FINAIS}

O livro "A História do Povo Terena" é fruto de um contexto de lutas pela autodeterminação dos povos indígenas que, dentre as reivindicações, chamam para si o direito de organizarem seu próprio processo educacional ${ }^{10}$. Trata-se de um contexto no qual vários povos, dentre eles, os Terena, passaram a agir, dada a ineficiência das políticas públicas que não colocam em prática direitos assegurados pela Constituição Federal de 1988.

A partir desse objeto de monografia, buscamos analisar, pela perspectiva Terena, seu desejo de se firmar como povo, constituindo uma identidade que perpassa tanto pelo conteúdo textual quanto icônico. Uma identidade que justifica a existência desse povo, constituindo uma unidade entre os membros dessa etnia. Neste trabalho, também buscamos observar a forma desse livro didático, pois a forma também incide no entendimento do conteúdo: "[...] a transformação das formas através das quais um texto é proposto autoriza recepções inéditas, logo cria novos públicos e novos usos" (CHARTIER, 1991, p. 11 ).

Esse é um livro que expressa a crença que os Terena depositam na educação como instrumento de transformação e afirmação de sua cultura, e também, a perspectiva de se inserirem na historiografia oficial, seja pela efetiva participação na Guerra do Paraguai, seja na construção das linhas telegráfica e férrea. Se em outros momentos a educação era vista como um mecanismo de doutrinação, hoje passa a ser um meio de libertação perante a realidade de exclusão (segundo a perspectiva Terena). Desse modo, são eleitos personagens e acontecimentos que não foram celebrados pela historiografia oficial.

Não se trata apenas de um livro feito para um povo, mas também, feito por um povo, que, por meio dos relatos orais, se tornam coautores de uma obra didática concebida com o auxilio da Academia. Claro que esse livro não resolve-

${ }_{10}$ Segundo Maria Elisa Ladeira me relatou em entrevista, no ano de 2013, este livro é considerado um best seller pelos Terena, sendo uma obra muito procurada por eles. 
rá todos os problemas ligados à questão indígena. Contudo, fornece subsídios para um despertar, apresentando aos alunos o tempo histórico, permeado por mudanças e continuidades. Um tempo resgatado também nas propostas de atividades que, ao estimularem a reflexão dos estudantes, os tornam também em autores, quando estes passam a reescrever as representações que têm do ambiente cotidiano.

Trata-se de um livro organizado, segundo as necessidades dos Terena. Demandas que se articulam com a chamada História do Tempo Presente, pois, nos dias atuais, essa comunidade enfrenta o problema da desagregação familiar, lembrando que o indígena precisa deixar a reserva para trabalhar nas áreas urbanas ou nas fazendas, localizadas no entorno, como fim de obter a subsistência. Dessa maneira, podemos entender esse livro não só como consequência de um processo constitucional, mas também, como um mecanismo que visa resgatar um modo de vida que pode um dia vir a desaparecer, ou seja, a tradição desses indígenas como agricultores, característica observada tanto na iconografia quanto no recolhimento dos relatos dos indígenas mais antigos.

\section{REFERÊNCIAS}

BITTENCOURT, Circe Maria Fernandes. Ensino de História: fundamentos e métodos. São Paulo: Cortez Editora, 2008.

BITTENCOURT, Circe Maria Fernandes. Entrevista. Acervo Pessoal. São Paulo, 2013.

BITTENCOURT, Circe Maria; LADEIRA, Maria Elisa. A história do povo Terena. Brasília: MEC/USP, 2000.

BRASIL. Ministério da Educação. Programa Nacional do Livro Didático - PNLD. Brasília, DF, 2011. p. 46-7.

BRASIL. Lei n. 11.645, de 10 de março de 2008. Inclui no currículo oficial da rede de ensino a obrigatoriedade da temática "História e Cultura Afro-Brasileira e Indígena". Brasília-DF, 2008.

CHAMUSCA, Adelaide; GESTEIRA, Kleber; GRILLO, Susana; HENRIQUES, Ricardo (Org.). Educação Escolar Indígena: diversidade sociocultural indígena ressignificando a escola. Cadernos Secad, Brasília, n. 3, p. 10-24, abril/2007. 
CHARTIER, Roger. O mundo como representação. Estudos avançados, v. 5, n. 11, São Paulo, p. 173-91, jan./abr. 1991. Disponível em: <http://www.scielo.br/scielo.php?script=sci_ar ttext\&pid=S0103-40141991000100010>. Acesso em: 10 dez. 2013.

CHOPPIN, Alain. História dos livros e das edições didáticas: sobre o estado da arte. Revista Educação e Pesquisa, São Paulo, v. 30, n. 3, p. 549-66, set./dez. 2004.

LADEIRA, Maria Elisa. Língua e História: análise sociolingüística em um grupo terena. 2001. Orientador: Erasmo D. Almeida Magalhães. Tese (Doutorado em Semiótica e Linguística Geral) - Universidade de São Paulo, São Paulo, 2001.

LADEIRA, Maria Elisa. Entrevista. Acervo Pessoal. São Paulo, 2013.

LEITE, Juçara Luzia. Construção identitária e livro didático regional de história: uma prática geracional de escrita de si. In: OLIVEIRA, Margarida Maria Dias de; STAMATTO, Maria Inês Sucupira (Org.). O livro didático de história: políticas educacionais, pesquisas e ensino. Natal: Editora da UFRN, 2007. p. 189-97.

TERENA, Mariano Marcos. O problema de fazer parte da comunidade brasileira enquanto brasileiros e enquanto membros de determinada etnia. Cadernos Ceru, São Paulo, n. 16, p. 33-45, 1981.

\section{Sobre o autor:}

Luciano Araújo Monteiro - Mestrando em História e Pós-graduando em Gestão Pública pela Universidade Federal de São Paulo (Unifesp). Assistente de Gestão e Políticas Públicas - Autarquia Hospitalar Municipal (AHM), Secretaria Municipal da Saúde da Prefeitura da Cidade de São Paulo. E-mail: lucianoaraujomonteiro@yahoo.com.br

Recebido em 12 de junho de 2018

Aprovado para publicação em 16 de novembro de 2018 
